\title{
Differential expression of miRNA-146a and miRNA-155 in gastritis induced by Helicobacter pylori infection in paediatric patients, adults, and an animal model
}

Ana Caren Cortés-Márquez 1,2,3, Sandra Mendoza-Elizalde ${ }^{1}$, Francisco Arenas-Huertero ${ }^{4}$, Jimena Trillo-Tinoco5, Pedro Valencia-Mayoral ${ }^{6}$, Alejandra Consuelo-Sánchez ${ }^{7}$, Jonathan Zarate-Franco ${ }^{8}$, Ada Ruth Dionicio-Avendaño ${ }^{9}$, José de Jesús Herrera-Esquivel ${ }^{9}$, Elio Germán Recinos-Carrera ${ }^{10}$, Christian Colín-Valverde ${ }^{1}$, Sandra Rivera-Gutiérrez ${ }^{3}$, Alfonso Reyes-López ${ }^{11}$, Juan Carlos Vigueras-Galindo ${ }^{1}$ and Norma Velázquez-Guadarrama ${ }^{1 *}$

\begin{abstract}
Background: Helicobacter pylori is a major aetiologic agent associated with gastritis. H. pylori infections increase the expression of the Toll-like receptor (TLR), which in turn modulates the expression of microRNA (miRNA)-146a and miRNA-155. The objective of this study was to compare the expression of miRNA-146a and miRNA-155 in gastric lesions of paediatric and adult patients with different pathologies and in Mongolian gerbils (Meriones unguiculatus) infected with H. pylori 26,695.
\end{abstract}

Methods: Quantification of miRNA expression was performed by quantitative real-time polymerase chain reaction (qRT-PCR) of paraffin-embedded gastric lesions of children with or without an infection $(n=25)$, adults with follicular gastritis and metaplasia $(n=32)$ and eight-week-old M. unguiculatus males (Hsd:MON) infected with H. pylori 26,695 for 0, 3, 6, 12 and 18 months $(n=25)$. The genes RNU48 and RNU6 were used as endogenous controls for data normalization. Statistical analyses were performed using Kruskal-Wallis, Mann-Whitney, ANOVA and Student's t-test.

Results: The expression of miRNA-146a and miRNA-155 in infected children increased by 247.6- and 79.4-fold (on average), respectively, compared to that observed in the control group. However, these results were not significant ( $p=0.12$ and $p=0.07$ respectively). In some children a gradual increase in expression was observed, while in others, expression was very high. Additionally, the expression levels of miRNA-146a and miRNA-155 increased by an average of 21.7- and 62-fold, respectively, in adult patients with follicular gastritis when compared to those of the controls. In M. unguiculatus infected with H. pylori 26,695, the expression of both miRNAs increased as the infection progressed.

Conclusion: This is the first report to show differences in the expression of miRNA-146a and miRNA-155 in paediatric and adult patients with gastritis who were infected with $H$. pylori. In addition, in M. unguiculatus infected with $\mathrm{H}$. pylori, miRNA expression was associated with the progression of infection and the ability of the bacteria to adapt to the host.

Keywords: Helicobacter pylori, Gastritis, miRNA-146a, miRNA-155, Meriones unguiculatus

\footnotetext{
* Correspondence: normave@himfg.edu.mx

${ }^{1}$ Infectology Laboratory, Hospital Infantil de México Federico Gómez, México

City, Mexico

Full list of author information is available at the end of the article
}

(c) The Author(s). 2018 Open Access This article is distributed under the terms of the Creative Commons Attribution 4.0 International License (http://creativecommons.org/licenses/by/4.0/), which permits unrestricted use, distribution, and reproduction in any medium, provided you give appropriate credit to the original author(s) and the source, provide a link to the Creative Commons license, and indicate if changes were made. The Creative Commons Public Domain Dedication waiver (http://creativecommons.org/publicdomain/zero/1.0/) applies to the data made available in this article, unless otherwise stated. 


\section{Background}

Helicobacter pylori is one of the primary etiological agents associated with gastritis, a condition characterized by inflammation of the lining of the stomach that is associated with mucosal lesions [1]. The progression of H. pylori infections is highly variable, and depending on the persistence of inflammation, it can lead to the development of acute gastritis or chronic active gastritis [1].

Patients infected with $H$. pylori develop acute gastritis that may resolve, a type of gastritis is associated with the development of hypochlorhydria and neutrophil infiltration. However, acute gastritis may also develop into chronic active gastritis, which is characterized by the infiltration of mononuclear cells, dominated by lymphocytes, plasma cells and macrophages. Additionally, acute gastritis may lead to multifocal chronic gastritis, for which there are many causes (genetics, age of acquisition, and virulence of the bacterial strain), and patients are frequently asymptomatic. In some individuals, multifocal chronic gastritis induces gastric atrophy and intestinal metaplasia, the latter of which is considered a risk factor for the development of dysplasia, which ultimately results in gastric cancer $[1,2]$.

microRNAs (miRNAs) are endogenous, non-coding RNAs that are 18 to 24 nucleotides in length and regulate post-transcriptional gene expression in animals and plants $[3,4]$ by participating in the regulation of various biological processes [3, 5-8]. The expression of many miRNAs are altered in numerous human diseases, such as cancer and immune and inflammatory disorders [4, 9]. In addition, they play important roles in host-parasite regulation, altering the host response to infection and the limiting the dissemination or replication of microorganisms. Specifically, in various infectious diseases, miRNAs regulate the host innate immune response $[10,11]$. Furthermore, to facilitate replication, microorganism may directly alter miRNA expression [12]. Matsushima et al. (2011) identified 31 miRNAs exhibiting differential expression in patients with $H$. pylori-infected gastric mucosa [8].

In adults, miRNA-146a and miRNA-155 are specifically involved in negatively regulating the pro-inflammatory immune response and are transcriptionally induced during $H$. pylori infection [13]. In particular, miRNA-146a is involved in the regulation of innate immunity and the $H$. pylori-induced inflammatory response, modulating the expression of target genes, such as IL-1 receptor associated kinase 1 (IRAK1) and tumour necrosis factor (TNF) receptor associated factor-6 (TRAF6). miRNA-155 is a crucial regulator of innate immunity and is expressed in a wide variety of immune cells during the inflammatory response, including macrophages, dendritic cells and several types of lymphocytes. During an $H$. pylori infection, miRNA-155 is transcriptionally induced in macrophages in response to Toll-like receptor (TLR) ligands or to TNF-alpha exposure in a manner that is dependent on transcription factors such as activator protein-1 (AP-1) and nuclear factor (NF-kB). However, no studies have described miRNA expression in the gastric mucosa of children in the context of $H$. pylori infections and the development of gastritis or during an infection in the model animal Meriones unguiculatus. Thus, in this study, we analysed the differential expression of miRNAs associated with $H$. pylori infection in paediatric and adult patients as well as in the M. unguiculatus animal model.

\section{Methods \\ Patients}

Selected gastric lesions from paraffin-embedded biopsy files at the Hospital Infantil de México Federico Gómez (HIMFG) Pathology Department were studied and distributed as follows: 16 children diagnosed with H. pylor$i$-induced gastritis and 9 children with gastritis without H. pylori, all of whom were admitted to the Department of Gastroenterology and Nutrition of the HIMFG. In addition, 37 adult patients from the Manuel Gea González General Hospital and the Gabriel Mancera Hospital were included, 32 of whom were infected with $H$. pylori (13 patients diagnosed with follicular gastritis and 19 with metaplasia) and 5 patients had gastritis without $H$. pylori.

\section{H. pylori infection in M. unguiculatus}

Twenty five 8-week-old M. unguiculatus males (Hsd:MON, Harlan Teklad, WI, USA) that weighted $40 \mathrm{~g}$ and were free of specific pathogens were used. The animals were obtained from the animal house of the Hospital Infantil de México Federico Gómez, México City. The Mongolian gerbils were maintained in plastic metabolic cages to prevent coprophagy under the same previously described conditions [14]. Free access to a standard diet (special rodent food; Harlan Teklad, WI, USA) and sterilized tap water were provided. The animals were euthanized by injection of a high dose of chemical anaesthetics (pentobarbital).

Animal care was performed in accordance with national and institutional policies (NOM-062-ZOO-1999) and the Guide for the Care and Use of Laboratory Animals for Animal Health and Well-being [15]. The Ethics, Biosafety and Scientific committees at the Health Institute approved the experiment (HIM/2011/080SSA 1005).

Each group of gerbils included five animals, ensuring that three of them would present $H$. pylori infection ([16]). Gerbils were inoculated intragastrically with $500 \mathrm{~mL} \mathrm{NaHCO} 3(0.2 \mathrm{M})$ and again $1 \mathrm{~h}$ later with a bacterial suspension of $H$. pylori $\left(6 \times 10^{8}\right.$ colony forming units $(\mathrm{CFU}) / \mathrm{mL})$ every day for one week. The gerbils 
were fasted $18 \mathrm{~h}$ prior to the first inoculation until the end of the fifth inoculation. The H. pylori strains used in this study included the reference strain 26,695 , and control animals received saline alone. The gerbils were euthanized at $0,3,6,12$ and 18 months by cervical dislocation under anaesthesia to harvest the stomachs. The stomach was dissected along the greater curvature and washed with phosphate-buffered saline (0.01 M PBS, $\mathrm{pH}$ 7.4). For each animal, one of the sections was fixed in $4 \%$ formaldehyde and embedded in paraffin blocks for subsequent histological analysis [14, 16].

\section{Histopathological analysis of injuries}

Gastric biopsies obtained from paediatric patients, adults and $M$. unguiculatus animals were paraffin-embedded, and histopathological sections were subsequently created. The sections were stained using a Giemsa and haematoxylin-eosin technique and were independently observed and evaluated by an experienced pathologist. Histopathological examination was performed to determine the degree of damage based on the updated Sydney system [17-19]. The parameters evaluated included $H$. pylori positivity, histological grade of neutrophil infiltration (activity), infiltration of mononuclear cells (chronic inflammation), glandular atrophy and intestinal metaplasia. These parameters were scored with ordinal values of $0,1,2$, and 3 , corresponding to null, mild, moderate and severe, respectively.

\section{Identification of $H$. pylori by detection of the $g / m M$ gene by PCR}

Paraffin-embedded biopsies were sectioned into $10-\mu \mathrm{m}$ thick slices, two of which were deposited into $1.5-\mathrm{ml}$ microcentrifuge tubes and dewaxed via immersion in xylene at $50{ }^{\circ} \mathrm{C}$, followed by absolute and $96 \%$ ethanol. Genomic DNA was extracted from cultured $H$. pylori using a Wizard Genomic DNA Purification Kit (Promega, Madison, WI, USA,) following the manufacturer's instructions. DNA was quantified using an Epoch Microplate Spectrophotometer (BioTek, Vermont, USA), and DNA integrity was evaluated by electrophoresis in $1 \%$ agarose gels. H. pylori was identified by the presence of the $g \operatorname{lm} M$ gene [20]. Amplification was performed in a reaction volume of $25 \mu \mathrm{L}$ of Master Mix (Promega) containing $100 \mathrm{ng}$ of bacterial DNA, $2.5 \mathrm{mM} \mathrm{MgCl} 2,10 \mathrm{mM}$ dNTPs, $2 \mathrm{U}$ of Taq DNA polymerase, 20 pmol of each primer and nuclease-free water in a Thermo Hybaid thermal cycler (PCR Express, CA, USA). The PCR products were separated by electrophoresis in $1 \%$ agarose gels at $80 \mathrm{~V}$, followed by staining with ethidium bromide and imaging under UV illumination (ChemiDoc transilluminator, BIO-RAD, USA). DNA from $H$. pylori ATCC strain 43,504 was included as a positive control and human DNA was used as a negative control.
Analysis of miRNA-146a and miRNA-155 expression by quantitative real-time polymerase chain reaction (qRTPCR)

Paraffin-embedded biopsies were sectioned into $10-\mu \mathrm{m}$ thick slices, two of which were deposited into $1.5-\mathrm{ml}$ microcentrifuge tubes and dewaxed via immersion in xylene at $50{ }^{\circ} \mathrm{C}$, followed by absolute and $96 \%$ ethanol. Total RNA was extracted using TRIzol $^{\circ}$ Reagent (Ambion RNA by Life Technologies; Carlsbad, California, USA), followed by a phenol:chloroform extraction. The quality and amount of the resulting RNA was assessed using a NanoDrop spectrophotometer (The Epoch ${ }^{\mathrm{Tm}}$ Multi-Volume Spectrophotometer System, WI. USA) at 260 and $280 \mathrm{~nm}$, respectively.

The expression of human and mouse miRNA-146a and miRNA-155 as well as two nucleolar RNAs (snoRNAs), RNU6 (present in humans and mice) and RNU48 (humans only), was measured by qRT-PCR. cDNA was synthesized from total RNA using TaqMan miRNA primers and a TaqMan ${ }^{\oplus}$ MicroRNA Reverse Transcription Kit from Applied Biosystems (Foster City, California, USA). For qRT-PCR, the pre-designed probes included with the TaqMan MicroRNA Life Technologies Assay Kit were used, which included primers and a TaqMan hybridization probe from Applied Biosystems (ID 000468, ID 002623, ID 001973 and ID 001006; ID 000468 and ID 002571 were mouse-specific), and the TaqMan $^{\circledR}$ Universal Master Mix II was used with uracil-N-glycosylase (UNG) $2 \times$ (Applied Biosystems Foster City, California, USA). Real-time PCR amplification was performed in triplicate under the following conditions: a 2 min incubation at $50{ }^{\circ} \mathrm{C}$ (for UNG activation) was followed by a $10 \mathrm{~min}$ incubation at $95{ }^{\circ} \mathrm{C}$ (for polymerase activation), after which 40 cycles of denaturation at $95{ }^{\circ} \mathrm{C}$ for $15 \mathrm{~s}$ and alignment and extension at $60{ }^{\circ} \mathrm{C}$ for 1 min using a Stratagene Mx3005p qPCR System and MxPro-Mx3005p software (Santa Clara, Calif., USA). The snoRNAs RNU6 and RNU48 were used as endogenous controls to normalize the data. The relative expression of the assayed miRNAs was calculated using the comparative 2- $\Delta \mathrm{Ct}$ method established by Pfaffl et al. (2004) [21].

\section{Statistical analysis}

Data analysis was performed using GraphPad Prism 6.0 (San Diego, CA, USA). ANOVA (Kruskal-Wallis) analyses of variance were used to analyse the statistical significance for unpaired groups, and multiple groups comparisons were performed using the Two-sample Wilcoxon rank-sum (Mann-Whitney U) test [Differences between groups of children with $H$. pylori-infected gastritis vs. children with uninfected gastritis and adults patients (with follicular gastritis and metaplasia) vs. adults with uninfected gastritis]. Differences with a $p$ value of 
$<0.005$ were considered significant. For animal model analyses, comparisons were made between the $M$. unguiculatus groups infected with $H$. pylori for different durations vs. the control $M$. unguiculatus group using a one-way ANOVA test, and differences were considered significant when $p<0.005$. Comparisons were made between $M$. unguiculatus groups at different stages of infection (0, 3, 6, 12 and 18 months) using Student's t-test. Differences with a $p$ value of $<0.005$ were considered significant.

\section{Results}

Sixty-two patients were included in this study. Among the 25 paediatric patients ( 16 males and 9 females), the minimum age was 2 years, the maximum age was 17 years, and the median age was 8 years and 8 months. Among the adults patients [ 20 males and 17 females], the minimum age was 24 years, the maximum age was 83 years, and the median age was 52 years and 2 months.

\section{Histopathological analysis}

H. pylori was identified in all infected groups by endpoint PCR. The results presented in Table 1 show the histopathological characteristics of paediatric patient biopsies based on the updated Sydney system. Of 25 paediatric patients with gastritis, $55.5 \%$ (5/9) of $H$. pylor$i$-negative infected children exhibited chronic gastritis, $22.25 \%(2 / 9)$ had chronic follicular gastritis, and 22.25\% $(2 / 9)$ had reactive gastropathy with intestinal metaplasia. In children testing positive for $H$. pylori infection, $62.5 \%$ $(10 / 16)$ had chronic gastritis and $25 \%(4 / 16)$ had chronic follicular gastritis, with two of these cases $(12.5 \%$ [2/16]) exhibiting reactive gastropathy.

Some of the histopathological findings observed in the gastric lesions of children infected with $H$. pylori, shown in Fig. 1, indicated the presence of $H$. pylori bacilli in the antral gastric mucosa as well as mucosal damage caused by the presence of inflammatory cells, which invade the gastric glands and promote the loss of their morphology and function.

In adult patients testing positive for $H$. pylori infection, chronic follicular gastritis was observed in 13 cases and reactive gastropathy with metaplasia in 19 cases, while adult patients without infection exhibited follicular gastritis.

\section{Expression of miRNA-146a and miRNA-155 in gastric lesions of children and adults infected with $H$. pylori} miRNA-146a and miRNA-155 were differentially expressed in the gastric lesions of children and adults infected with $H$. pylori (Fig. 2). The detailed of expression of miRNA-146a and miRNA-155 and data patients (age and sex) are listed in Additional file 1: Table S1.

The relative expression levels of miRNA-146a and miRNA-155 in paediatric patients infected with $H$. pylori were 247.6- and 79.4-fold greater than those observed in uninfected patients, respectively. Increased miRNA expression was observed with respect to gastritis activity. For example, in non-active gastritis, we observed a 1.53-fold increase in the relative expression of miRNA-146a, whereas in patients exhibiting severe gastritis, miRNA-146a expression increased 935.7-fold. Similar results were observed for miRNA-155, which was increased 0.12-fold in non-active gastritis and up to 66.25-fold in severe gastritis. Although

Table 1 Histological characteristics of gastric lesions in children with gastritis without H. pylori (negative) and children with gastritis who were infected with H. pylori (positive) based on the updated Sydney system

\begin{tabular}{|c|c|c|c|c|c|}
\hline Gastritis & Infection with $\mathrm{H}$. pylori & $N=25$ & Activity & Atrophy & Metaplasia \\
\hline Chronic & Negative & $5(55.5 \%)$ & 1 & $\mathrm{~L}$ & $\mathrm{~N}$ \\
\hline Follicular chronic & Negative & $2(22.25 \%)$ & 0 & $\mathrm{~N}$ & $\mathrm{~N}$ \\
\hline Reactive gastropathy & Negative & $2(22.25 \%)$ & 0 & N & Intestinal \\
\hline \multirow[t]{5}{*}{ Chronic } & Positive & $10(62.5 \%)$ & & & \\
\hline & & (4) & 1 & N & N \\
\hline & & (2) & 1 & L & \\
\hline & & (2) & 2 & L & \\
\hline & & (2) & 2 & M & \\
\hline \multirow[t]{4}{*}{ Follicular chronic } & Positive & $4(25 \%)$ & & & \\
\hline & & (2) & 0 & N & $\mathrm{N}$ \\
\hline & & (1) & 0 & L & \\
\hline & & (1) & 1 & L & \\
\hline Reactive gastropathy & Positive & $2(12.5 \%)$ & 1 & $\mathrm{~N}$ & $\mathrm{~N}$ \\
\hline
\end{tabular}




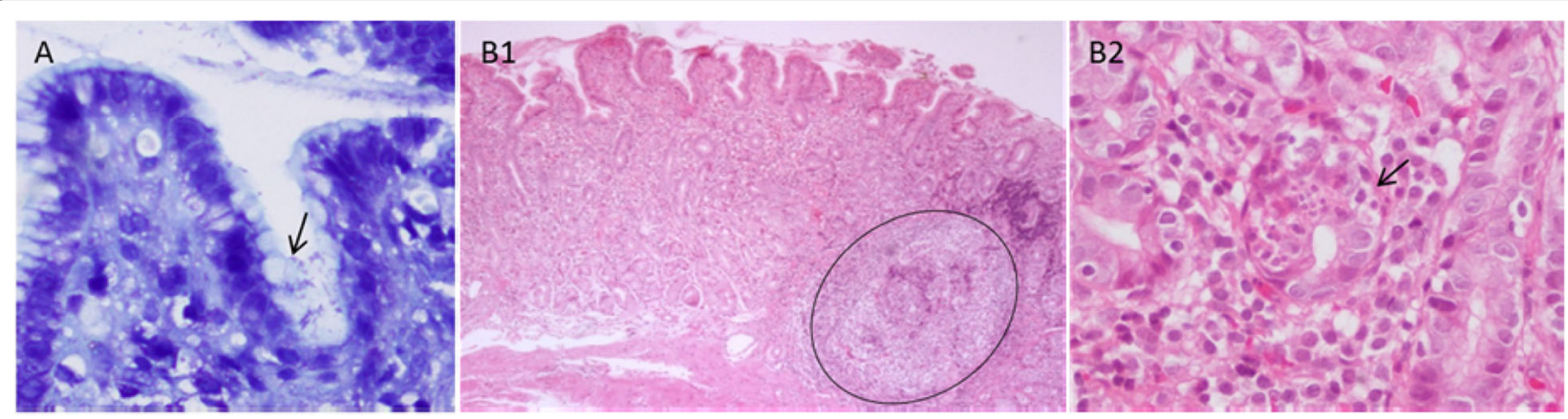

Fig. 1 a H. pylori bacilli infecting the mucosal surface of an antral gland, marked with an arrow. Giemsa stain (60x). b1, b2 Chronic follicular gastritis with moderate atrophy of the gastric mucosa, moderate activity, the absence of metaplasia, and associated with $\mathrm{H}$. pylori. Chronic follicular gastritis was characterized by the presence of intraepithelial polymorph nuclear inflammatory infiltration, expansion of the lamina propria at the expense of a dense mixed infiltrate consisting of both polymorph nuclear and mononuclear lymphocytes and plasma cells, and the formation of lymphoid follicles with germinal centres (arrows and circles) (haematoxylin-eosin), observed at 10x and 60x magnification

the average miRNA-146 and miRNA-155 expression increased greatly in the mucosa of $H$. pylori-positive paediatric patients with gastritis, these differences were not significant ( $p=0.12$ and 0.07 , respectively).

Adult patients infected with $H$. pylori exhibited increased relative expression levels of miRNA-146a and miRNA-155 (21.79- and 62-fold, respectively) in follicular gastritis compared to that observed in uninfected adult patients. In addition, in patients infected with metaplasia, 7.5- and 124.5-fold increases in the relative expression levels of miRNA-146a and miRNA-155 were observed compared to those seen in uninfected patients, respectively. The average increase in miRNA-146 and miRNA-155 expression was significant for follicular

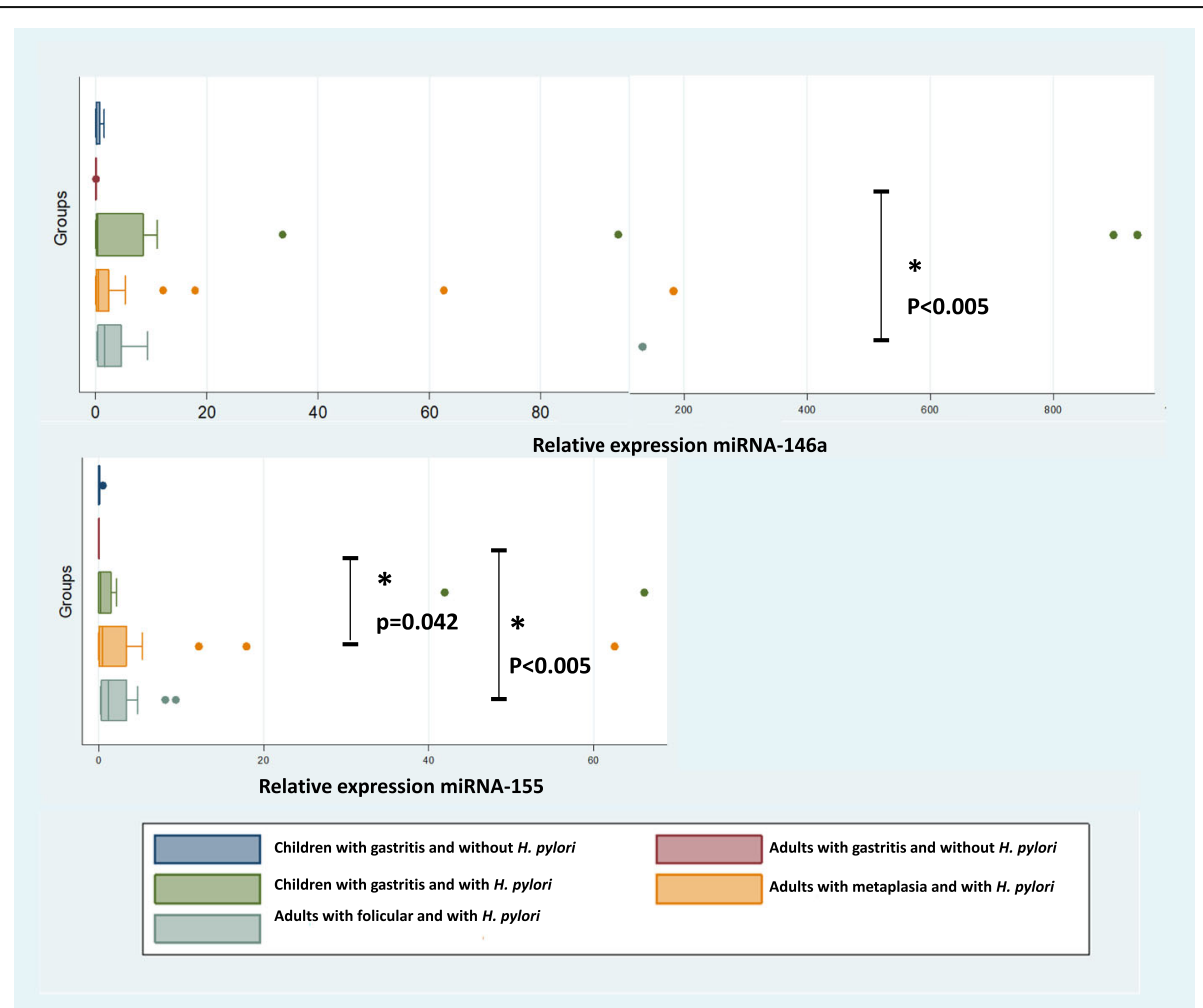

Fig. 2 miRNA expression in human gastric tissue. Expression of miRNA-146a and miRNA-155 was determined in the gastric lesions of $H$. pylori children and adults as well as H. pylori children and adults with gastritis by performing qRT-PCR (a, b). miRNA levels were normalized to RNU48 and RNU6 levels. The median, maximum and minimum values of three independent experiments are shown. The data are presented as box-whisker plots (box, 25-50\%, whiskers, 5-95\%, and line, median). ${ }^{* *} p<0.005$ 
gastritis $(p<0.005)$ and metaplasia $(\mathrm{p}=0.93$ and 0.042 , respectively).

\section{Histopathological analysis of gastric lesions in $M$. unguiculatus}

Table 2 shows the histopathological results for the gastric lesions observed in $M$. unguiculatus during different stages of $H$. pylori infection. After 3 months of infection, a mild development of gastritis was observed, which increased to moderate and severe activity with atrophy over time (6,12 and 18 months).

Differential expression of miRNA-146a and miRNA-155 in gastric lesions of $M$. unguiculatus infected with $H$. pylori In gastric lesions of $M$. unguiculatus infected with $H$. pylori 26,695, the expression of miRNA-146 increased throughout the duration of the infection. However, a significant difference was only observed at 18 months when compared to the uninfected group. In contrast, miRNA-155 expression levels were detected after 6 months of infection. miRNA-146a expression levels increased over time by 1.32-, 1.92-, 6.83- and 10.54-fold $(p<0.005)$ at $3,6,12$ and 18 months, respectively, and by 1.19-, 1.79 - and 3.04-fold, respectively $(p<0.005)$, when compared to those in the uninfected group. miRNA-155 expression levels increased slightly compared to those observed in the uninfected group (Fig. 3).

\section{Discussion}

$H$. pylori infection is acquired during childhood and persists into adulthood. Infected individuals may develop gastritis, and various studies have demonstrated a relationship between gastritis and altered miRNA expression, specifically altered expression of various miRNAs in the gastric lesions of adult patients infected with $H$. pylori $[8,22,23]$. However, there have been no reports of miRNA expression levels in children infected with this bacterium.

In this first study conducted in paediatric patients with $H$. pylori-infected gastritis, the results showed that the relative expression levels of miRNA-146a and miRNA-155

Table 2 Histological characteristics of gastric lesions in $M$. unguiculatus infected with $H$. pylori based on the updated Sydney System

\begin{tabular}{lllll}
\hline Stage of infection & $\begin{array}{l}\text { Length of Infection } \\
\text { (months) }\end{array}$ & Activity & Atrophy & Metaplasia \\
\hline Control & 0 & 0 & 0 & 0 \\
Colonization & 3 & 1 & $\mathrm{~N}$ & $\mathrm{~N}$ \\
Persistence & 6 & 2 & $\mathrm{~L}$ & $\mathrm{~N}$ \\
Chronicity & 12 & 3 & $\mathrm{M}$ & $\mathrm{N}$ \\
Chronicity & 18 & 3 & $\mathrm{M}$ & $\mathrm{L}$ \\
\hline
\end{tabular}

Activity: 0 (null); 1 (mild); 2 (Moderate); 3(severe) $N$ Negative, $L$ Light, $M$ Moderate in paediatric patients infected with $H$. pylori were folds-greater when compared to those observed in uninfected patients. However, the differences were not significant. The above results occurred because during $H$. pylori infection, the gastric epithelial cells recognize the TLRs of the bacteria and may then activate a series of inflammation-related signalling pathways. For example, $H$. pylori- bacterial lipopolysaccharide (LPS), a cell wall component, is recognized primarily by TLR4 [24]. TLR4 can activate the myeloid differentiation primary-response gene 88 (MyD88), leading to the translocation of NF- $\mathrm{BB}$ into the nucleus, which subsequently activates the expression of genes related to the inflammatory process. Similarly, several TLR ligands have been shown to increase miR-155 expression via MyD88 [25]. However, studies of $H$. pylor$i$-infected children have not indicated the occurrence of changes in the expression of natural immunity receptors such as TLR2 and TLR4 as well as the adapter protein MyD88, unlike in adult patients [26].

In children infected with $H$. pylori, the host response is characterized by an increase in lymphocytic infiltration in the gastric mucosa and a high expression of anti-inflammatory mediators. Such a response is related to the tolerance of macrophages and dendritic cells, which contributes to the formation of different suppressor T cells, including Tregs, Tr1 and Th3 cells [27]. In contrast, miRNAs are involved in the downregulation of pro-inflammatory cytokines through the attenuation of NF- $\kappa B$ [28], including miRNA-146a-mediated immunological tolerance and T-cell differentiation mediated by miRNA-155 [29]. This potentially explains the gradually increased levels of miRNA expression observed in infected paediatric patients. In particular, in three patients overexpressing miRNA-146a and miRNA-155, moderate to severe active gastritis was observed, and the presence of parasites was ruled out. This suggests that the miRNA overexpression in these patients is closely related to lymphocytic infiltration.

The results obtained for miRNA-146a and miRNA155 expression in the tissue of adults with follicular gastritis agrees with the findings of Xiao et al. (2009), Liu et al. (2010) and Lario et al. (2012), who reported that miRNA expression increased in the lesions of patients with infected gastritis compared to those with normal gastric mucosa (without gastritis). Specifically, for miRNA-146a in tissue infected with $H$. pylori [22, 23, 30]. In addition, there have been reports of a correlation between miRNA-146a and miRNA-155 expression, which are overexpressed in gastric lesions with $H$. pylori. TLRs play an important role in maintaining gastric mucosal homeostasis, and TLRs signal through the adaptor molecule MYD88 after $H$. pylori recognition, which activates downstream factors to coordinate the upregulation of several functionally distinct gene subsets. In 


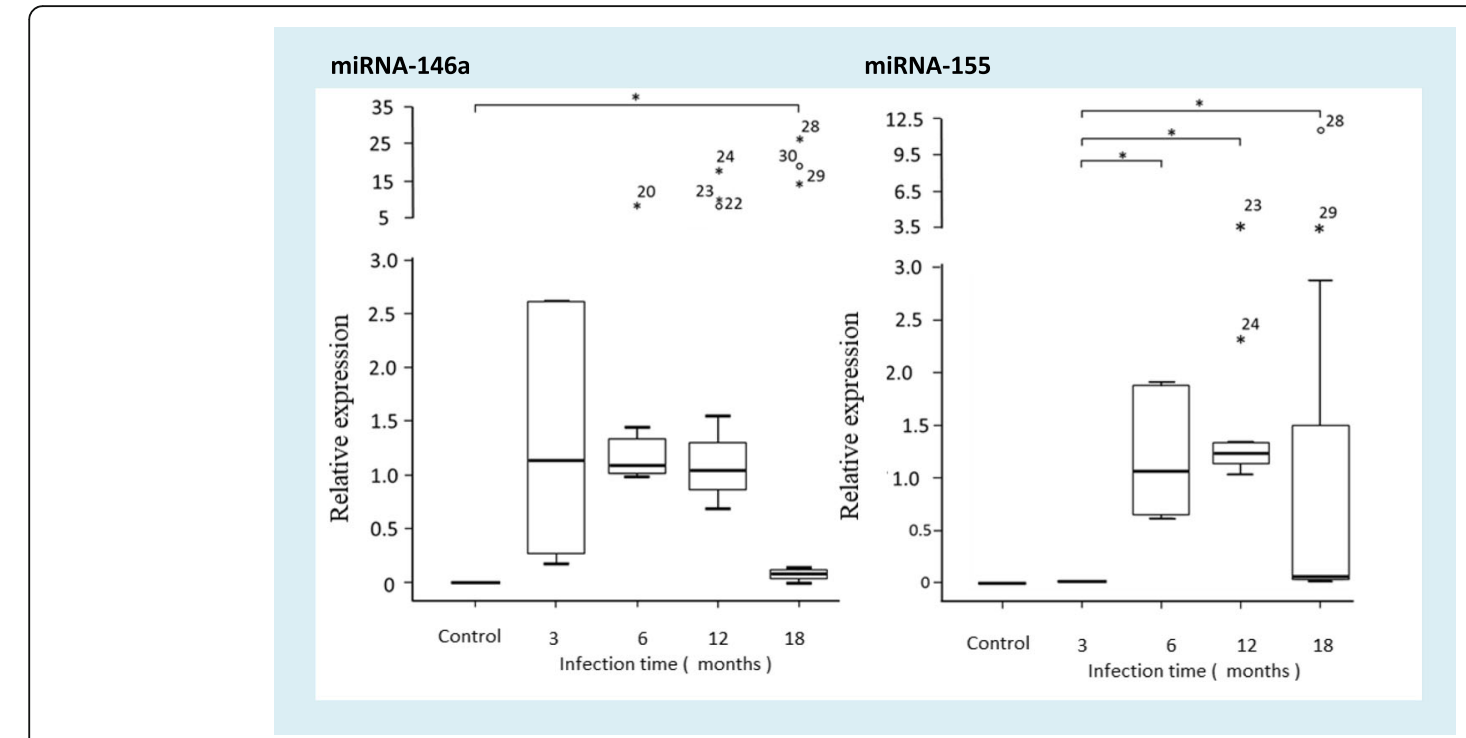

miRNA-155

Fig. 3 miRNA expression in gastric lesions of M. unguiculatus. Expression of miRNA-146a and miRNA-155 was determined in the gastric lesions of M. unguiculatus infected with H. pylori 26,695 for 3, 6, 12 and 18 months and in $H$. pylori (-) M. unguiculatus by performing qRT-PCR. miRNA levels were normalized to RNU6 levels. The median, maximum and minimum values of three independent experiments are shown. The data are presented as box-whisker plots

particular, miRNA-146a and miRNA-155 are regulated by TLR in different cell types, some of which fine-tune the control of TLR signalling components $[24,25]$.

The expression of miRNA-146a is altered in some types of tumours [31], particularly in gastric cancer, where it acts as a tumour suppressor by inhibiting cell migration and invasion [32]. In addition, miRNA-155 acts as an oncogenic miRNA (oncomiR), and the expression of miRNA-155 is increased in different types of leukaemia, lymphomas and solid tumours of various origins. The expression levels of miRNA-155 are higher than those of miRNA-146a in these diseases, whereas in this study, we observed that miRNA-146a and miRNA-155 are not expressed in patients with metaplasia, which is considered a preneoplastic lesion. miRNAs have different levels of expression in gastric cancer tissues that perform different functions. Li et al. (2014), observed significantly lower expression levels of miRNA-155 in gastric carcinomas than those of corresponding non-tumour gastric tissues [33]. The negative regulation of miRNA-155 accelerates cell growth and directs the invasion of c-myc into human gastric carcinoma cells [34]. c-Myc serves as a pro-oncogene that is closely related to tumourigenesis and sustained tumour growth [35]. Therefore, miRNA-155 can function as a gastric tumour suppressor during the development of gastric carcinoma. Thus, the regulation of miRNA-155 during gastric tumourigenesis is a complicated and poorly understood.

Different animal models have been developed to study H. pylori infection, including rats and different strains of mice that have been successfully infected with this bacterium. However, the study of gastric pathologies induced by $H$. pylori has been difficult to describe because the available models are able to resolve infection and do not develop pathology. Hirayama et al. (1996) reported another rodent infection model, $M$. unguiculatus, commonly known as the Mongolian gerbil [36]. In this model, bacteria are detected for long periods of time and produce lesions, such as active chronic gastritis, peptic ulcers and intestinal metaplasia, similar to those generated in humans. This model is also capable of developing gastric carcinogenicity using a carcinogenic agent, such as $\mathrm{N}$-methyl-N-nitrosourea in conjunction with $H$. pylori. Despite the various advantages of this model with respect to infection, there have been no reports of the expression of $H$. pylori-induced miRNAs in M. unguiculatus. Thus, this is the first report to describe the expression of miRNAs, specifically miRNA-146a and miRNA-155, in $M$. unguiculatus infected with this bacterium at different time points. In addition, the results of this study showed that these miRNAs are expressed and continue to increase throughout the infection. However, our model had limitations, and we determined that miRNA expression levels in $M$. unguiculatus are much lower relative to those observed in humans This may be related to the chronicity of the infection, because the period of infection in M. unguiculatus is short (3 to 18 months) compared to the course of chronic human infections, which occur over much longer periods of time, spanning approximately 20 years from the acquisition of bacteria to the establishment of disease. 
Previous studies performed by our group have demonstrated that infection with $H$. pylori strain 26,695 in $M$. unguiculatus is subject to changes over time due to the loss or acquisition of genetic material via genetic recombination events [16]. We also suggest that the bacterium undergoes an adaptation process in the gastric mucosa of the animal model, because important intragenic changes and few histological changes are observed in the gastric mucosa. This observation may be related to the slight increase in genetic changes observed throughout the infectious process. Philpott et al. (2002) reported that some strains of $H$. pylori can adapt in mice [37]. Such adaptation prevents the bacteria from causing damage to the mucosa due to a significant reduction in the inflammatory process in the gastric mucosa, indicated by the inability to induce the secretion of pro-inflammatory cytokines.

Several studies have suggested that chronic gastritis is associated with the alteration of miRNA-155 and reported a gradual increase trend of miRNA-155 expression in preneoplastic gastric mucosa, indicating that miRNA-155 is essential to the persistent inflammation of gastric mucosa [38-40]. Similarly, in chronic gastritis it was observed that overexpression of miRNA-146a could significantly decrease the activity of the nuclear factor-kappa B (NF- $\kappa \mathrm{B})$ pathway, suggesting that miRNA-146a may play a crucial role in a negative feedback loop to modulate gastric mucosal inflammation [22].

\section{Conclusion}

In this study, we showed that the increased expression of miRNA-146a and miRNA-155 is associated with the duration and outcome (follicular gastritis or metaplasia) of $H$. pylori infection. In humans, $H$. pylori induces a persistent chronic infection, during which the gastric epithelial cells recognize the TLRs of the bacteria and then may activate a series of inflammation-related signalling pathways., In addition, the loss or acquisition of genes by this bacterium facilitate its survival and persistence within the host. Therefore, it is important to consider this during the $H$. pylori infectious process in paediatric patients, as important changes are taking place during this developmental period. In addition, the differential expression of miRNAs, specifically miRNA-146a and miRNA-155, which we demonstrated are associated with gastritis and undergo important changes in expression in both paediatric patients and adults, is indicative of the chronicity of infection and disease severity.

\section{Additional file}

Additional file 1: Table S1. Expression of miRNA-146a and miRNA-155 in the gastric lesions of children and adults infected with and without H. pylori. miRNA levels were normalized to RNU48 and RNU6 levels. (XLSX $19 \mathrm{~kb})$

\section{Abbreviations}

AP-1: Activator protein-1; CFU: Colony forming units; IFNy: Interferon gamma; IRAK1 : IL-1 receptor associated kinase 1; miRNA: microRNA; MyD88: Myeloid differentiation primary response 88; NF-kB: Nuclear factor; oncomiR: Oncogenic miRNA; qRT-PCR: Quantitative real-time polymerase chain reaction; RNU48: Nucleolar RNAs (humans only); RNU6: Nucleolar RNAs (present in humans and mice); snoRNAs: Small nucleolar RNAs; TLR: Toll-like receptor; TNF: Tumour Necrosis factor; TRAF6: Receptor associated factor-6; TREM1: Triggering receptor expressed on myeloid cells 1; UNG: Uracil-Nglycosylase

\section{Acknowledgements}

The authors gratefully acknowledge the CONACyT. Postgraduate in Biomedicine and Molecular Biotechnology (ENCB-IPN). And Department of Research and Postgraduate (SIP). This work was part of ACCM's PhD dissertation, and she was a CONACYT (290040) fellow.

\section{Funding}

This study was supported by the Federal Resources from the Ministry of Health and Assistance (SSA), México. Project number: HIM/2013/009-SSA 1081 and HIM/2011/080-SSA 1005. The funders had no role in the study design, data collection and analysis, decision to publish, or preparation of the manuscript.

\section{Availability of data and materials}

All data generated or analysed during this study are included in the published article.

\section{Authors' contributions}

ACCM and NVG designed the experiments, interpreted the data and wrote the manuscript. ACCM and JTT analysed and interpreted the data from patients. FAH and SRG made substantial contributions to conception of study. SME and PVM performed experiments using the animal model. ACS, JZF, RDA, JHE and GRC diagnosed, treated and included the patients in the study. CCV contributed to data analyses and interpretation. ARL made substantial contributions to analysis and interpretation of data. JCVG been involved in drafting the manuscript. All authors revised and approved the final manuscript.

\section{Ethics approval and consent to participate}

The parents or guardians of the paediatric patients and the individuals who participated were informed regarding the nature of the study and gave their written consent (HIM-LC-RC-PR. 01).

The ethics (Dr. Luis Jasso Hernández: Chairman of the Committee), biosafety (Dra. Herlinda Vera Hermosillo: Chairman of the Committee) and scientific committees (Dr. Onofre Muñoz Hernández: Chairman of the Committee) at the Health Institute (HIMFG) approved the study protocols in advance to patients (HIM/2013/009-SSA 1081) and to animals (HIM/2011/080- SSA 1005). Our study was conducted according to the principles enshrined in the Declaration of Helsinki. And animal care was performed in accordance with national and institutional policies (NOM-062-ZOO-1999) and the Guide for the Care and Use of Laboratory Animals for Animal Health and Well-being.

\section{Consent for publication}

Not Applicable.

\section{Competing interests}

The authors declare that they have no competing interests.

\section{Publisher's Note}

Springer Nature remains neutral with regard to jurisdictional claims in published maps and institutional affiliations.

\section{Author details}

${ }^{1}$ Infectology Laboratory, Hospital Infantil de México Federico Gómez, México City, Mexico. ${ }^{2}$ Biomedicine and Molecular Biotechnology, Escuela Nacional de Ciencias Biológicas, Instituto Politécnico Nacional, México City, Mexico. ${ }^{3}$ Molecular Microbiology Laboratory, Microbiology Department, Escuela Nacional de Ciencias Biológicas, Instituto Politécnico Nacional, México City, Mexico. ${ }^{4}$ Laboratory of Research in Experimental Pathology, Hospital Infantil de México Federico Gómez, México City, Mexico. ${ }^{5}$ Department of 
Immunology, Moffitt Cancer Center, Tampa, FL, USA. ${ }^{6}$ Planning Direction, Hospital Infantil de México Federico Gómez, México City, Mexico.

${ }^{7}$ Gastroenterology and Nutrition Department, Hospital Infantil de México Federico Gómez, México City, Mexico. ${ }^{8}$ Health Science, Escuela Superior de Medicina, Instituto Politécnico Nacional, México City, Mexico. ${ }^{9}$ Endoscopy Department, Hopital General Dr. Manuel Gea González, México City, Mexico. ${ }^{10}$ Division of Pathological Anatomy, Hospital General Dr. Manuel Gea González, México City, Mexico. ${ }^{11}$ Center of Economic and Social Studies in Health, Hospital Infantil de México Federico Gómez, México City, Mexico.

Received: 19 January 2018 Accepted: 30 August 2018

Published online: 15 September 2018

\section{References}

1. Sepulveda AR. Helicobacter, inflammation, and gastric Cancer. Curr Pathobiol Rep. 2013;1:9-18.

2. Beltrán-Anaya FO, Manuel Poblete T, Román-Román A, Reyes $\mathrm{S}$, de Sampedro J, Peralta-Zaragoza O, et al. The EPIYA-ABCC motif pattern in CagA of Helicobacter pylori is associated with peptic ulcer and gastric cancer in Mexican population. BMC Gastroenterol. 2014;14:223.

3. Bartel DP. MicroRNAs: genomics, biogenesis, mechanism, and function. Cell. 2004;116:281-97.

4. Slezak-Prochazka I, Durmus S, Kroesen BL, van den Berg A. MicroRNAs, macrocontrol: regulation of miRNA processing. RNA. 2010;16:1087-95.

5. Ambros V. The functions of animal microRNAs. Nature. 2004;431:350-5.

6. Macfarlane LA, Murphy PR. MicroRNA: biogenesis, function and role in Cancer. Curr Genomics. 2010;11:537-61.

7. Bartel DP. MicroRNAs: target recognition and regulatory functions. Cell. 2009;136:215-33.

8. Matsushima K, Isomoto H, Inoue N, Nakayama T, Hayashi T, Nakayama M, et al. MicroRNA signatures in Helicobacter pylori-infected gastric mucosa. Int J Cancer. 2011;128:361-70.

9. Wu F, Zikusoka M, Trindade A, Dassopoulos T, Harris ML, Bayless TM, et al. MicroRNAs are differentially expressed in ulcerative colitis and alter expression of macrophage inflammatory peptide-2 alpha. Gastroenterology. 2008;135:1624-35.

10. Eulalio A, Schulte L, Vogel J. The mammalian microRNA response to bacterial infections. RNA Biol. 2012;9:742-50.

11. Staedel C, Darfeuille F. MicroRNAs and bacterial infection. Cell Microbiol. 2013;15:1496-507.

12. Zhang, Ying-ke L. MicroRNAs in the regulation of inmune response against infections. J Zhejiang Univ Sci B. 2013;14:1-7.

13. Noto MJ, Peek RM Jr. Helicobacter species. Methods Mol Biol. 2012;921:7-10.

14. Mendoza-Elizalde S, Arteaga-Resendiz NK, Valencia-Mayoral P, Luna RC, Moreno-Espinosa S, Arenas-Huertero F, et al. Diversification of the vacAs $1 \mathrm{~m} 1$ and vacAs2m2 strains of Helicobacter pylori in Meriones unguiculatus. Front Microbiol. 2016;7:1758.

15. National Research Council. Guide for the Care and Used of Laboratory Animals: Eighth Edition. Washington, DC: The National Academies Press; 2011. https://doi.org/10.17226/12910

16. Velazquez-Guadarrama N, Olivares A, Valencia P, De los Monteros L, Madrigal-Santillán E, Madrigal-Bujaidar E. Genotoxic and oxidative damage induced by Helicobacter pylori in Meriones unguiculatus. J Environ Pathol Toxicol Oncol. 2007;26:39-49.

17. Dixon MF, Genta RM, Yardley JH, Correa P. Classification and grading of gastritis. The updated Sydney system. International workshop on the histopathology of gastritis, Houston 1994. Am J Surg Pathol. 1996;20:1161-81.

18. Akanuma M, Maeda S, Ogura K, Mitsuno Y, Hirata Y, Ikenoue T, Otsuka M, et al. The evaluation of putative virulence factors of Helicobacter pylori for gastroduodenal disease by use of a short-term Mongolian gerbil infection model. J Infect Dis. 2002;185:341-7.

19. Nakagawa S, Osaki T, Fujioka Y, Yamaguchi H, Kamiya S. Long-term infection of mongolian gerbils with Helicobacter pylori: microbiological, histopathological, and serological analyses. Clin Diagn Lab Immunol. 2005;12:347-53.

20. Smith SI, Oyedeji KS, Arigbabu AO, Cantet F, Megraud F, Ojo OO, et al. Comparison of three PCR methods for detection of Helicobacter pylori DNA and detection of cagA gene in gastric biopsy specimens. World J Gastroenterol. 2004;10:1958-60.

21. Pfaffl MW. Quantification strategies in real-time PCR. In: Bustin SA Editor. A-Z of quantitative PCR. International University Line (IUL), La Jolla. 2004. http:// www.gene-quantification.de/chapter-3-pfaffl.pdf. Accessed 25 July 2015.
22. Liu Z, Tang B, Li B, Li N, Zhu E, et al. Up-regulated microRNA-146a negatively modulate Helicobacter pylori-induced inflammatory response in human gastric epithelial cells. Microbes Infect. 2010;12:854-63.

23. Xiao B, Liu Z, Li BS, Tang B, Li W, Guo G, et al. Induction of microRNA-155 during Helicobacter pylori infection and its negative regulatory role in the inflammatory response. J Infect Dis. 2009;200:916-25.

24. Matsuura M. Structural modifications of bacterial lipopolysaccharide that facilitate gram-negative bacteria evasion of host innate immunity. Front Immunol. 2013;4:109.

25. O'Connell RM, Taganov KD, Boldin MP, Cheng G, Baltimore D. MicroRNA-155 is induced during the macrophage inflammatory response. Proc Natl Acad Sci USA. 2007;104:1604-9.

26. Michalkiewicz J, Helmin-Basa A, Grzywa R, Czerwionka-Szaflarska M, Szaflarska-Poplawska A, Mierzwa G, et al. Innate Immunity Components and Cytokines in Gastric Mucosa in Children with Helicobacter pylori Infection. Mediators Inflamm. 2015;2015:ID176726:1-7.

27. Belair C, Baud J, Chabas S, Sharma CM, Vogel J, Staedel C, et al. Helicobacter pylori interferes with an embryonic stem cell micro RNA cluster to block cell cycle progression. Silence. 2011;2:1-7.

28. Gracias DT, Stelekati E, Hope JL, Boesteanu AC, Doering TA, Norton J, et al. The microRNA miR-155 controls CD8(+) T cell responses by regulating interferon signaling. Nat Immunol. 2013;14:593-602.

29. Androulidaki A, lliopoulos D, Arranz A, Doxaki C, Schworer S, Zacharioudaki $V$, et al. The kinase Akt1 controls macrophage response to lipopolysaccharide by regulating microRNAs. Immunity. 2009;31:220-31.

30. Lario S, Ramírez-Lázaro MJ, Aransay AM, Lozano JJ, Montserrat A, Casalots Á, et al. microRNA profiling in duodenal ulcer disease caused by Helicobacter pylori infection in a Western population. Clin Microbiol Infect. 2012;18:E273-82.

31. Yao Q, Cao Z, Tu C, Zhao Y, Liu H, Zhang S. MicroRNA-146a acts as a metastasis suppressor in gastric cancer by targeting WASF2. Cancer Lett. 2013;335:219-24.

32. Elton TS, Selemon H, Elton SM, Parinandi NL. Regulation of the MIR155 host gene in physiological and pathological processes. Gene. 2013;532:1-12.

33. Li H, Xie S, Liu M, Chen Z, Liu X, Wang L, et al. The clinical significance of downregulation of miR-124-3p, miR-146a-5p, miR-155-5p and miR-335-5p in gastric cancer tumorigenesis. Int J Oncol. 2014;45:197-208.

34. Sun $S$, Sun P, Wang C, Sun T. Downregulation of microRNA-155 accelerates cell growth and invasion by targetingc-myc in human gastric carcinoma cells. Oncol Rep. 2014:32:951-6.

35. Lin CY, Loven J, Rahl PB, Paranal RM, Burge CB, Bradner JE, et al. Transcriptional amplification in tumor cells with elevated c-Myc. Cell. 2012;151:56-67.

36. Hirayama F, Takagi S, Yokoyama Y, Iwao E, Ikeda Y. Establishment of gastric Helicobacter pylori infection in Mongolian gerbils. J Gastroenterol. 1996; 31(Suppl 9):24-8.

37. Philpott DJ, Belaid D, Troubadour P, Thiberge J-M, Tankovic J, Labigne A, et al. Reduced activation of inflammatory responses in host cells by mouseadapted Helicobacter pylori isolates. Cell Microbiol. 2002;4:285-96.

38. Petrocca F, Visone R, Onelli MR, Shah MH, Nicoloso MS, de Martino I, et al. E2F1-regulated MicroRNAs impair TGF -dependent cell-cycle arrest and apoptosis in gastric cancer. Cancer Cell. 2008;13:272-86.

39. Rodriguez A, Vigorito E, Clare S, Warren MV, Couttet P, Soond DR, et al. Requirement of bic/ microRNA-155 for normal immune function. Science. 2007;316:608-11.

40. Chen S, Wang L, Fan J, Ye C, Domiguez D, Zhang Y, et al. Host miR155 promotes tumor growth through a myeloid-derived suppressor celldependent mechanism. Cancer Res. 2015;75:519-31.

\section{Ready to submit your research? Choose BMC and benefit from:}

- fast, convenient online submission

- thorough peer review by experienced researchers in your field

- rapid publication on acceptance

- support for research data, including large and complex data types

- gold Open Access which fosters wider collaboration and increased citations

- maximum visibility for your research: over $100 \mathrm{M}$ website views per year

At $\mathrm{BMC}$, research is always in progress.

Learn more biomedcentral.com/submissions 